\title{
Message Reading through Eye Blinking
}

\author{
Tribhuwan Kumar Tewari \\ Sr. Lecturer \\ Jaypee Institute of Information \\ Technology, \\ Sector 62. Noida
}

\author{
Anshul Arya \\ Jaypee Institute of Information \\ Technology, \\ Sector 62,Noida
}

\author{
Sameer Rastogi \\ Jaypee Institute of Information \\ Technology, \\ Sector 62,Noida
}

\begin{abstract}
In this paper we propose an Eye-Asseto System to help the paralytic patients with the daily life scheduling. Eye-Asseto is a system designed with special focus on the paralytic patients. We presume that the targeted user would be able to use his eye and mind in the worst case even when his hands and other body parts are not working. The paper discusses how Eye-Asseto works merely with Eye-blinking using minimal resources and efforts from the side of the user. The systems, thus aims to make the life of the paralytic patients by simply offering them a user friendly and cost effective solution, to be used to plan the daily activities. We use the name of Eye-Asseto for our system for the very reason that eye acts as an asset to a paralytic person to fully operate the proposed system.
\end{abstract}

\section{General Terms}

Input channel, user interaction, eye blink, user adaptiveness and sarcades

\section{Keywords}

Low Cost, user friendly, Eye-Asseto, Infra Red Transmitter/Receiver

\section{INTRODUCTION}

Eye blink detection has long heralded many possible uses and values. Here the key is to separate the natural eye blinks which we refer as the sarcades from the intentional eye blinks [1]. In general, people's eyes are constantly sensitive to light intensity which causes the natural eye blinks. The less sensitive pair of IR transmitter and receiver can be used to neglect the effect of the natural eye blinks. Successful scenarios require the benefits of the interaction to outweigh the difficult requirements on eyes. The hardware interface has to be user friendly which doesn't put stress on the user. Moreover, we don't expect the specific behavior from the user to operate the system.

Typical computer devices (keyboard and mouse) can be described as explicit input channels because they require a direct manipulation of the user. Alternatively, implicit input channels gather information without user interaction. EyeAsseto is designed to look at eye blink and imply intention from ambient activity taking references from Eye-R system proposed by Ted Selker [2]. As the user is intentionally manipulating the input to the system but through eye blink, it can be considered as an explicit channel.

The system comprises of the two modules- Help user and Paralytic Patient. The paralytic patient may only view different information available to him and use eye blinks to access that information. He may also read his mails, set the alarm and many more without using mouse or keyboard. But the help user may feed the data into the system making use of input devices.

\section{CURRENT STATE OF ART}

Before arriving at our proposal various research works was done by us. We learnt from the previous contemporary systems that they either required highly extensive biological modifications in the brain, like placing chips in the brain etc. as we saw in case of BRAINGATE. After studying this paper we came to know that such biological activities based systems are too expensive and thus not affordable to a common man [3]. Also, there have been many face tracking systems developed for handicapped persons, but it would be practically impossible for a paralytic patient to use such systems if they are unable to move their head. Time to time many research took place to detect face moments and use them to operate the systems [4].

Since eye lid is quite sensitive part of the body, paralytic patients have their control over it, so we decided to use this advantage to develop a cost effective system that will benefit the paralytic patients in managing their daily schedules, setting alarms etc [1].

We studied Midas touch \& Staggered Speech available to handicapped people that are free on-screen keyboard. These existing systems had their own disadvantages as they did not recognise when the user does not want to make a selection of available options. We have addressed this problem in the proposed system [5].

A study on Active Appearance Model was also done. Active Appearance modelling is used to recognize facial expressions in still pictures and videos through the camera. We came to know that this process of extraction of relevant information is very time consuming, complicated and very expensive [6].

We in this project focus specially on the basic and daily needs of a disabled person. Our objective is to construct a low cost very easy to use infrared Transmitter/Receiver circuit, and interface this circuit using suitable amplifier to PC parallel port for detection and develop a backend system to read the explicit input received through IR receiver and perform the tasks accordingly. The flickering of eye gives an obstruction to the receiver. This project will be based on the detection and decoding of the same. The electronic circuit used here would be an IR (infra-red) Transmitter \& Receiver.

Below in the table(see table 1), we have discussed different contemporary systems available to the handicapped along with their features and drawbacks. The drawbacks are the motivation for a new low cost improved system. 


\section{Table 1- Contemporary Systems for handicaps}

\begin{tabular}{|c|c|c|}
\hline TECHNIQUE & FEATURES & DRAWBACKS \\
\hline $\begin{array}{c}\text { MIDAS TOUCH } \\
{[5]}\end{array}$ & $\begin{array}{l}\text { - } \quad \text { Free onscreen keyboard program. } \\
\text { - } \quad \text { Camera Mouse uses dwell time to click. } \\
\text { - Entire message automatically is copied } \\
\text { whenever letter is copied. }\end{array}$ & $\begin{array}{l}\text { - If mouse pointer is held on certain spot } \\
\text { on the screen for } 1 \text { second a click is } \\
\text { issued by Camera Mouse. } \\
\text { - A key on which the mouse pointer } \\
\text { dwells can be clicked by mistake. }\end{array}$ \\
\hline $\begin{array}{c}\text { STAGGERED } \\
\text { SPEECH } \\
\text { [7] }\end{array}$ & $\begin{array}{l}\text { - Two-level keyboard program that is based } \\
\text { on the spelling system. } \\
\text { First choose the group that contains the } \\
\text { desired letter and then one choose the } \\
\text { particular letter in that group. } \\
\text { Message can be saved as a standard text } \\
\text { file in File menu. }\end{array}$ & $\begin{array}{l}\text { - Move head from left to right or vice } \\
\text { versa is next to impossible. } \\
\text { - Disabled person finds it easy to flick } \\
\text { their eyes rather than moving their } \\
\text { head. }\end{array}$ \\
\hline $\begin{array}{c}\text { EYE TECH } \\
\text { DIGITAL } \\
\text { SYSTEM }\end{array}$ & $\begin{array}{l}\text { - Camera mounted on computer monitor and } \\
\text { is focused on user's eye. } \\
\text { Quick Glance determines where the user is } \\
\text { looking, the gaze point Cursor is placed at } \\
\text { the gaze point. } \\
\text { "Mouse clicks" are done with a slow eye } \\
\text { blink, an eye dwell, or a hardware switch. } \\
\text { - Unique assistive technologies devise. }\end{array}$ & $\begin{array}{l}\text { - Cursor moves according to the user's } \\
\text { eye movements which again might } \\
\text { cause problem to the disabled person } \\
\text { because eye movement can be a cause } \\
\text { of worry for the user. } \\
\text { - If there would have been blinking of } \\
\text { eye that would have made the job of } \\
\text { patient much easier. }\end{array}$ \\
\hline
\end{tabular}




\begin{tabular}{|c|c|c|}
\hline $\begin{array}{c}\text { HEAD } \\
\text { TRACKING } \\
\text { MOUSE } \\
{[8]}\end{array}$ & $\begin{array}{l}\text { - It is a device transmitting a signal from } \\
\text { atop the computer monitor and tracking a } \\
\text { reflector placed on the user's head. } \\
\text { - A mouse alternative as this allows the } \\
\text { person control over the movement of } \\
\text { cursor, using only the movement of his } \\
\text { head. } \\
\text { The movement of the user's head relates to } \\
\text { what direction the onscreen cursor will } \\
\text { travel. }\end{array}$ & $\begin{array}{l}\text { - A mouse alternative this only provides } \\
\text { the individual control over mouse } \\
\text { movements. } \\
\text { - It does not provide the mouse functions } \\
\text { such as a mouse "click". } \\
\text { - Also the movement of head is another } \\
\text { next to impossible task for the user. }\end{array}$ \\
\hline $\begin{array}{c}\text { ACTIVE } \\
\text { APPEARANCE } \\
\text { MODEL }\end{array}$ & $\begin{array}{l}\text { - AAM technique is used to extract relevant } \\
\text { information regarding the shapes of the } \\
\text { faces to be analyzed. } \\
\text { - Specific key points from a Facial } \\
\text { Characteristic Point - FCP model are used } \\
\text { to derive the set of features. } \\
\text { A database is created which consists of } \\
\text { sequence of recordings of subjects acting } \\
\text { on multiple scenarios. }\end{array}$ & $\begin{array}{l}\text { - This process of extraction of relevant } \\
\text { information is very time consuming. } \\
\text { - It is also very expensive. }\end{array}$ \\
\hline
\end{tabular}

\section{SYSTEM DESIGN}

The system is designed to be battery operated and be able to mount on any common pair of the glass. While the input from the system into the computer would be taken through the parallel port through pin number 2-9 [9]. The infrared Emitter-Detector pair is positioned between the lens and Eye. The IR Transmitter used is of the frequency $38 \mathrm{~Hz}$.

The eye pupil acts as a reflector and when the eye is open, the detector continuously receives the input while on an eye blink there is no reflection back to the detector which gives an input to the system [10].

In IR detector and transmitter circuit the IC 555 is working under monostable mode [11]. As soon as the IR light beam transmitted is obstructed, a momentary pulse actuates the relay output (or LED). The IR transmitter is simple series connected resistor network from battery. The timing capacitor connected to pin 6 and 7 to ground. The time can varied as per requirement by changing the $R$ value [12].

Below is the data flow diagram constituting the entire flow of information to the system and with in the system

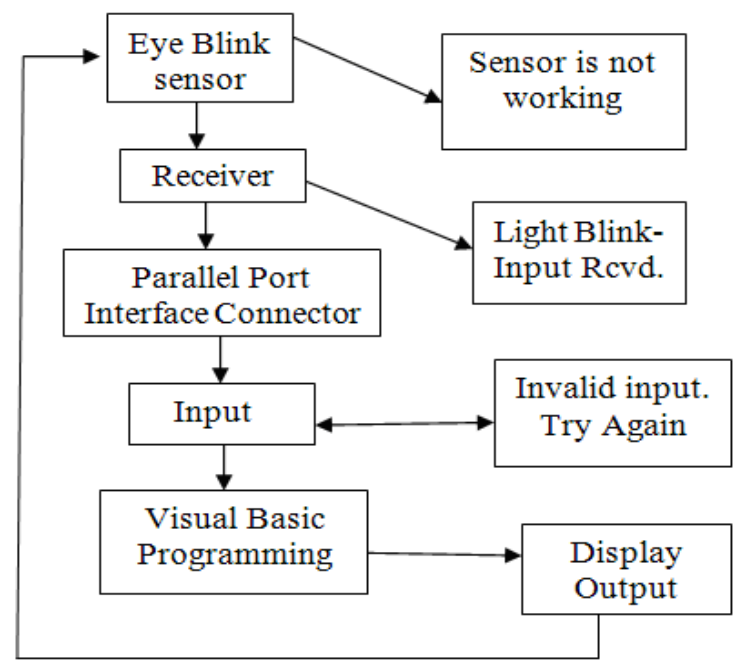

Figure 2 Data flow diagram of the system 


\subsection{Scenario}

In general, Eye-Asseto glasses worn by a user detects the eye blinks and interprets this as the user paying attention to something in the immediate environment. The glasses then try to establish communication with a target in the environment to alert the target of the user's attention. The target responds to the user and records this interaction.

The input given by the user can be taken into the computer through the parallel port and thus user can operate the computer through Eye blinks. This would enable the paralytic patient to plan out his daily activities on the computer though it would also require the constant assistant of the help user who would be the normal person. Even the worst paralytic patient can use the system as in the worst case; the paralytic person can move his eye lid. This would also enable multi tasking in this high-tech world. When one's hands are engaged into different activities, one may still be able to do different tasks using his eyes.

In both the cases, there will be a series of codes that can be assigned to different activities user may be able to do using the Eye-Asseto system. For any activity that user may do, there will be a specific code that would be known to the user and the user can insert that code using the eye blinks. To keep the system simple, the activity number would be represented by exactly the same number of blinks. For instance, three eye-blinks would correspond to the third activity. Each blink would pass "1" and a timer of 1 second runs in the background to detect the number of blinks. If the counter stops, and there is no eye blink detected, a " 0 " would be passed to the system. The system would stop counting as soon as the zero is encountered and the corresponding activity would be displayed.

\section{FUTURE WORK}

The Eye-Asseto system would serve as the basic infrastructure for various applications. The eye blinking will be expanded to include face moments, eye moments and pattern recognition. The ability to detect eye moments and face moments can then be a useful tool in gathering information about the user state such as stress and fatigue and about the user intentions implicitly. In the later stages, the system can be made more user adaptive by developing the user interest patterns and change in the interests according to external factors such as time, climate etc.

\section{CONCLUSION}

The Eye-Asseto system allows the researchers to experiment with the eye-blinking and demonstrates that an inexpensive eye blink system can be made. It shows the eye blinking can be robustly detected even in the unstable format of being mounted on a pair of glasses. This system has the huge potential to be exploited both by the researchers and commercially as well.

\section{REFERENCES}

[1] Greg Edwards "A Tool for Creating Eye-aware Applications that Adapt to Changes in User Behavior
"Proceedings of the third international ACM conference on Assistive technologies ,1998, pp 67-74 ,ISBN:1-58113-020-1.

[2] Ted Selker, Andrea Lockered, Jorge Martinez "Eye-R, a Glasses-Mounted Eye Motion Detection Interface" Conference on Human Factors in Computing Systems CHI'01,pp: 179 - 180 ,2001,ISBN:1-58113-340-5.

[3] Vidal, JJ (1973). "Toward direct brain-computer communication". Annual review of biophysics and bioengineering ,1973,pp 2157-80.

[4] Robert J.K. Jacob "What you look at is what you get Eye Movement Based Interaction Techniques" Conference on Human Factors in Computing, 1990,page 11-18,1990.

[5] Charles R.Blair "On Computer Transcription of Manual Morse “,Journal of the ACM (JACM), 1959, Volume 6, Issue 3 ,pp 429 - 442 , ISSN:0004-5411.

[6] Drago Datcu Léon Rothkrantz "Facial Expression Recognition in still pictures and videos using Active Appearance Models: a comparison approach", Proceedings of the 2007 international conference on Computer systems and technologies ,2007, Article No.: 112 , ISBN:978-954-9641-50-9.

[7] Daniel S. Beasley, Barry A.F "Lead and Lag Effects Associated with the Staggered Spondaic Word Test", Journal of Speech and Hearing Research 1976 Vol.19, pp 572-577.

[8] James W. Davis, Serge Vaks “A Perceptual User Interface for Recognizing Head Gesture Acknowledgements", Proceedings of the 2001 workshop on Perceptive user interfaces ,2001,pp 1-7.

[9] C.F. Soon, S.Y. Leong1 and Nicholas Tan "'Quadriplegic Communicator for Spinal Cord Injury Patient" 3rd Kuala Lumpur International Conference on Biomedical Engineering 2006 ,pp. 647-650,ISSN 1680-0737.

[10] Christopher S. Campbell "A Robust Algorithm for Reading Detection" Proceedings of the 2001 workshop on Perceptive user interfaces 2001, ACM International Conference Proceeding Series, Vol. 15,pp 1-7.

[11] Sarvani Kare, Ashok Samal ,David Marx "Using bidimensional regression to assess face similarity", Journal of Machine Vision and Apllications,2010,Volume 21,Number 3, pp 261274,ISSN 1432-1769.

[12] Zhiwei Zhu "Real Time Eye Detection and Tracking under Various Light Conditions" Proceedings of the 2002 symposium on Eye tracking research \& applications,2002,PP 139-144,ISBN:1-58113-467-3. 